\title{
BMJ Global Health The magnitude and determinants of violence against healthcare workers in Pakistan
}

\author{
Shiraz Shaikh, ${ }^{1}$ Lubna Ansari Baig, ${ }^{2}$ Ibrahim Hashmi, ${ }^{1}$ Mirwais Khan, ${ }^{3}$ \\ Seemin Jamali, ${ }^{4}$ Muhammad Naseem Khan, ${ }^{5}$ Munir Akhtar Saleemi, ${ }^{6}$ \\ Komal Zulfiqar, ${ }^{7}$ Sumera Ehsan, ${ }^{8}$ Iram Yasir, ${ }^{7}$ Zia ul Haq, ${ }^{5}$ Lubna Mazharullah, ${ }^{1}$ \\ Samina Zaib ${ }^{1}$
}

To cite: Shaikh S, Baig LA, Hashmi I, et al. The magnitude and determinants of violence against healthcare workers in Pakistan. BMJ Global Health 2020;5:e002112. doi:10.1136/ bmjgh-2019-002112

\section{Handling editor Kerry Scott}

Received 25 October 2019 Revised 8 February 2020 Accepted 7 March 2020

Check for updates

(C) Author(s) (or their employer(s)) 2020. Re-use permitted under CC BY-NC. No commercial re-use. See rights and permissions. Published by BMJ

${ }^{1}$ APPNA Institute of Public Health Jinnah Sindh Medical University, Karachi, Sindh, Pakistan

${ }^{2}$ Public Health, APPNA Institute of Public Health Jinnah Sindh Medical University, Karachi, Pakistan

${ }^{3}$ International Committee of the Red Cross Pakistan, Islamabad, Islamabad, Pakistan

${ }^{4}$ Jinnah Postgraduate Medical Centre, Karachi, Pakistan ${ }^{5}$ Khyber Medical University, Peshawar, Pakistan

${ }^{6}$ The University of Lahore University College of Medicine and Dentistry, Lahore, Pakistan ${ }^{7}$ Al Nafees Medical College and Hospital, Islamabad, Islamabad, Pakistan

${ }^{8}$ University Medical and Dental College Faisalabad, Punjab, Pakistan

Correspondence to

Dr Shiraz Shaikh;

shiraz.shaikh@jsmu.edu.pk

\section{ABSTRACT}

Objectives To determine the magnitude and determinants of violence against healthcare workers (HCWs) and to identify the predominant types and causes of violence experienced by them. Methodology A cross-sectional survey based on structured questionnaire adopted from previous surveys and qualitative data was conducted in 4 large cities and 12 districts in 3 provinces of Pakistan. The survey covered 8579 from all cadres of HCWs, including doctors, nurses, technicians, support staff, ambulance workers, vaccinators, lady health visitors, midwives and lady health workers (LHWs). The predictors of overall violence experienced physical violence experienced and verbal violence experienced were separately analysed for tertiary care hospitals, secondary care hospitals, primary care hospitals and field-level HCWs. Logistic regression was used to compute adjusted ORs with $95 \%$ Cls for the association of different factors with the violence experienced. Results More than one-third (38.4\%) reported having experienced any form of violence in the last 6 months. Verbal violence was the most commonly experienced form $(33.9 \%)$, followed by physical violence (6.6\%). The main reasons for physical violence were death of patients $(17.6 \%)$, serious condition of patients (16.6\%) and delay in care (13.4\%). Among the different types of field HCWs, emergency vehicle operators were significantly more likely to experience verbal violence compared with LHWs (adjusted OR=1.97; 95\% $\mathrm{Cl} 1.31$ to 2.94; $\mathrm{p}=0.001$ ). Among hospital HCWs, those working in private hospitals were significantly less likely to experience physical violence (adjusted $\mathrm{OR}=0.52 ; 95 \% \mathrm{Cl} 0.38$ to $0.71 ; \mathrm{p}=0.001$ ) and verbal violence (adjusted OR=0.57; $95 \% \mathrm{Cl} 0.48$ to 0.68 ; $\mathrm{p}=0.001$ ). Conclusion Violence against HCWs exists in various forms among all cadres and at different levels of care. The gaps in capacity, resources and policies are evident. Specific strategies need to be adopted for different types of HCWs to protect them against violence.

*The study was conducted under the framework of ICRC's Healthcare in Danger Initiative for protection of healthcare against Violence

\section{INTRODUCTION}

Violence as defined by WHO is 'the intentional use of physical force or power, threatened or actual, against oneself, another person, or against a group or community, which either results in or has a high likelihood of resulting in injury, death, psychological harm, mal-development or deprivation'.

\section{Key questions}

What is already known?

- Previous studies on violence have mostly been on small scale involving one or few cadres of HCW's.

What are the new findings?

- Main reasons among hospital HCW's included reaction of attendants to adverse outcomes, impatient behavior of patients and attendants, delay in care and lack of facilities

- Among ambulance workers, main reasons included delay in arrival and shifting of the patient and lack of facilities to provide good quality pre-hospital emergency care

- Among field healthcare workers, misconception of vaccines was the main reason.

- This study proposes interventions according to main reasons of violence.

What do the findings imply?

- The findings of the study provide directions for different healthcare settings on how to protect HCW's.

- The essential interventions required are increasing resources to provide good quality of care, introducing policies to improve responsiveness to patient's needs, training HCW's in communication and deescalation skills and introducing educational and regulatory measures to improve patient and attendant behavio

Workplace violence has been defined as 'any incident where staff are abused, threatened or assaulted in circumstances relating to their work involving an explicit or implicit challenge to their safety, well-being and health'. ${ }^{2}$ Almost a quarter of workplace violence occurs within the healthcare sector. ${ }^{3}$ Violence against healthcare workers (HCWs) is a global phenomenon and was declared a major public health problem in the FortyNinth World Health Assembly in 1996. ${ }^{4}$ Many countries have reported high incidence of 
physical and verbal violence especially in the emergency departments. ${ }^{5-10}$ HCWs are mostly susceptible to reactive violence from patients and their attendants, affecting their mental and physical well-being. ${ }^{11}$ If the workers are stressed about security, it can lead to post-traumatic stress disorder and can decrease job performance and increase burn-out. This also negatively impacts patients who are deprived of good-quality care responsive to their genuine needs in time of trouble. ${ }^{12}$ Research studies and press reports in Pakistan have highlighted the issue of violence against healthcare providers, in which they have been subjected to all forms of violence ranging from verbal and physical misbehaviour to even threats of extortion and kidnapping for ransom. ${ }^{13-15}$ To add to that, many doctors have been killed either for ransom or have been targeted on religious, ethnic and sectarian grounds. ${ }^{16} 17$ As a result of lack of secure environments, outmigration of healthcare providers from the country has also become common and the performance of health sector has been deeply affected. ${ }^{18}$

The International Committee of the Red Cross within the framework of its global initiative, Health Care in Danger (HCiD), seeks to improve the protection of patients, medical personnel, facilities and vehicles from violence through humanitarian diplomacy, advocacy, promotion of law and practical interventions. A largescale, multicentre research in Karachi in 2015 found out that around one-third of all healthcare providers experienced any kind of violence in the past 12 months. ${ }^{19} 20$ Keeping in view the endemic nature of the problem and HCiD initiative's commitment to protect HCWs all over Pakistan, there was a need to highlight the issue at a larger scale and to understand in detail the dimensions of the issue at different levels of care. Therefore, this survey was conducted in three provinces of Pakistan to identify solutions that are applicable on a wider scale. The main objectives of this survey were to determine the magnitude and determinants of violence against HCWs and to identify the predominant types and causes of violence experienced by them.

\section{METHODS}

\section{Study design, population and setting}

A cross-sectional survey based on a structured questionnaire was conducted in four large cities of Pakistan, namely Islamabad, Peshawar, Lahore and Karachi, and four randomly sampled districts each in three provinces of Pakistan (Sindh, Punjab and Khyber Pakhtunkhwa). The project was led by HCiD partner in Karachi, that is, APPNA Institute of Public Health, Jinnah Sindh Medical University, in collaboration with Al-Nafees Medical College (Isra University) Islamabad, University of Lahore (Punjab), Khyber Medical University (Khyber Pakhtunkhwa) and Faisalabad Medical University.

The survey covered all cadres of HCWs, including doctors, nurses, technicians, support staff (clerical, security and housekeeping staff), ambulance staff, vaccinators, lady health visitors, midwives and lady health workers (LHWs). The study started in January 2018 and was completed by the end of the year.

\section{Sample size and sampling}

Sample size was estimated with the assumption that an expected $33.5 \%$ of HCWs would be experiencing violence taken from a previous study in Karachi,${ }^{20}$ with $\pm 1 \%$ accuracy and $95 \%$ confidence level; the sample size came out to be 8486 HCWs. Due to budget constraints, data could be collected in any five cities in each of the three provinces (capital cities and districts) and the federal capital. Since the population of provincial capitals and federal capital is more than double the average population in any district, $1000 \mathrm{HCW}$ sere selected from each of the four large cities (three provincial capitals and one federal capital) and 400 HCWs were selected from four randomly selected districts in each province, collectively amounting to a sample size of $8800 \mathrm{HCWs}$. The districts were chosen from four different divisional regions of each province to ensure adjustment for socioeconomic variability and accessibility to healthcare facilities. One district was randomly chosen from each of the provincial regions.

Distribution of sample size between different cadres was based on covering at least 10\% of the HCWs from the expected number of HCWs in each of the settings. For example if there were 50 sanctioned positions of a doctor in a secondary care facility, we covered at least five doctors from that facility. In the four large cities, hospital staff including doctors, nurses, technicians and support staff were sampled from three public and three private sector hospitals. Within each hospital, equal numbers of HCWs were taken from emergency, medical, surgical, paediatric, and gynaecology and obstetrics departments. Ambulance staff were stratified into technical staff and vehicle operators. Equal numbers of vaccinators were randomly chosen from 10 different coverage areas of the city. Equal numbers of LHWs were randomly chosen from 10 different coverage areas of the city.

In the 12 districts, hospital staff including doctors, nurses, technicians and support staff were equally sampled from public and private settings. All three tiers of public sector at the district level, including district headquarter hospital, tehsil health units and basic health units, were involved. Similarly, private settings of both district and tehsil levels were included. Ambulance staff were equally distributed among major service providers (both public and private sector) and were also stratified equally into technical staff and vehicle operators. Equal numbers of vaccinators and LHWs were randomly chosen from 10 different coverage areas of the district.

\section{Patient and public involvement}

A baseline qualitative study was conducted with the target study population to construct the structured questionnaire. However, the HCWs were not directly involved in the design and conduct of the study due to 
the cross-sectional nature of the study. As per plan, the study findings will be shared with the administrators of the different sites where the study was conducted.

\section{Data collection methods}

Data collection was allocated on a daily basis with data collectors given a set of sites already planned by the data supervisors. The survey team gathered in the field office every morning, prepared the strategy for the day and left for the field. After completing fieldwork the team came back to the office, checked their work for completeness and errors, and submitted it to data supervisors. If any errors and inconsistencies were identified, the forms were given back to the data collectors for correction in the field. Scheduled and surprise monitoring visits were made by regional coimplementers at all sites. As the data were collected by trained data collectors and all respondents complied after discussion on their apprehensions, we had $100 \%$ response rate.

The questionnaire was adopted from previous surveys done in Karachi and Peshawar and was modified based on the findings of a baseline qualitative study. As the original studies were done in major cities and missed the rural and suburban context, qualitative study was done for contextualisation. Two indepth interviews (IDIs) and two focus group discussions (FGDs) were conducted with HCWs and administrators in each of the three provinces. The IDIs were conducted with the administrators, while the FGDs involved hospital HCWs, including doctors, nurses and technicians, as well as field HCWs including LHWs and vaccinators. Thematic content analysis provided insights on the description of violence and its reasons, which helped in finalising the questionnaire. Section 1 of the questionnaire obtained information on demographic and occupational characteristics of the participant, including age, gender, workplace and years of experience. Section 2 gathered information on any form of violence experienced or witnessed in the last 6 months, for example, number of events, nature of the event, reason and perpetrators.

\section{Statistical analysis}

Data were collected from 8756 individuals, of whom 177 had missing information. Therefore the final analysis was done on 8579 HCWs. Demographics and job characteristics were summarised as frequency and percentages for categorical variables and means and SD for continuous variables. Frequencies and percentages of overall violence and their types experienced and witnessed were also computed.

The predictors of overall violence experienced, physical violence experienced and verbal violence experienced were separately analysed for tertiary care hospital, secondary care hospitals, primary care hospitals and field HCWs. Logistic regression was used to compute adjusted ORs with $95 \%$ CIs to determine the association of different factors with the three outcomes mentioned above. The independent variables included age, work experience,
Table 1 Descriptive characteristics of healthcare workers $(\mathrm{n}=8579)$

\begin{tabular}{|lc}
\hline Age, mean 33.19, SD 8.86 & \\
\hline $18-29$ & $42.2 \%(3618)$ \\
\hline $30-44$ & $44.8 \%(3842)$ \\
\hline 45 and above & $13.0 \%(1119)$ \\
\hline Gender & \\
\hline Male & $55.6 \%(4770)$ \\
\hline Female & $44.4 \%(3809)$ \\
\hline Religion & \\
\hline Islam & $94.6 \%(8114)$ \\
\hline Christianity & $4.1 \%(350)$ \\
\hline Hinduism & $1.3 \%(109)$ \\
\hline Others & $0.1 \%(6)$ \\
\hline Province & \\
\hline Sindh & $30.8 \%(2641)$ \\
\hline Punjab & $29.9 \%(2563)$ \\
\hline Khyber Pakhtunkhwa & $28.2 \%(2419)$ \\
\hline Federal Capital & $11.1 \%(956)$ \\
\hline Major language & \\
\hline Urdu & $21.7 \%(1860)$ \\
\hline Sindhi & $17.1 \%(1470)$ \\
\hline Punjabi & $29.2 \%(2509)$ \\
\hline Hindko & $23.7 \%(2035)$ \\
\hline Others & $0.6 \%(51)$ \\
\hline
\end{tabular}

gender, province, city, type of hospital (public or private), hospital departments, cadre of HCWs and security index (categorised as low, medium and high). Principal component analysis was used to compute hospital security index based on data gathered on 27 items related to hospital security and field security index based on 12 items related to field security.

\section{RESULTS}

Table 1 shows the descriptive characteristics of the HCWs. The mean age of the participants was $33.19 \pm 8.86$ years. Men $(55.6 \%)$ outnumbered women $(44.4 \%)$. Majority of the respondents were Muslims (94.6\%), with a fairly equal representation from the three provinces.

Table 2 shows the common forms of violence experienced. Almost half (49.2\%) of the participants had either experienced or witnessed any kind of violence and more than one-third $(38.4 \%)$ reported having experienced any form of violence in the last 6 months. On average each HCW experienced 4.15 events and witnessed 1.58 events of violence in the last 6 months. Verbal violence was the most commonly experienced form $(33.9 \%)$, followed 


\begin{tabular}{|c|c|c|}
\hline & Experienced & Witnessed \\
\hline $\begin{array}{l}\text { Verbal violence } \\
\text { (abused/shouted at/ } \\
\text { threatened) }\end{array}$ & $\begin{array}{l}33.9 \%(2909) \\
\text { Mean=3.93, } \\
S D=8.83\end{array}$ & $\begin{array}{l}18.4 \%(1578) \\
\text { Mean }=1.43 \\
S D=4.90\end{array}$ \\
\hline $\begin{array}{l}\text { Physical violence (beaten/ } \\
\text { pushed/thrown things at) }\end{array}$ & $\begin{array}{l}6.6 \%(567) \\
\text { Mean=0.12, } \\
S D=0.59\end{array}$ & $\begin{array}{l}5.2 \%(446) \\
\text { Mean }=0.12 \\
S D=0.71\end{array}$ \\
\hline Falsely accused & $\begin{array}{l}2.2 \%(189) \\
\text { Mean }=0.06 \\
S D=0.55\end{array}$ & $\begin{array}{l}0.7 \%(63) \\
\text { Mean }=0.01 \\
S D=0.19\end{array}$ \\
\hline Bullied/harassed & $\begin{array}{l}1.1 \%(91) \\
\text { Mean=0.023, } \\
S D=0.281\end{array}$ & $\begin{array}{l}0.4 \%(35) \\
\text { Mean=0.01, } \\
S D=0.095\end{array}$ \\
\hline $\begin{array}{l}\text { Shown or attacked with } \\
\text { weapon }\end{array}$ & $\begin{array}{l}0.7 \%(57) \\
\text { Mean }=0.006 \\
S D=0.081\end{array}$ & $\begin{array}{l}0.3 \%(29) \\
\text { Mean }=0.00 \\
S D=0.085\end{array}$ \\
\hline Damage to facility & $\begin{array}{l}0.4 \%(36) \\
\text { Mean=0.01, } \\
S D=0.11\end{array}$ & $\begin{array}{l}0.3 \%(25) \\
\text { Mean=0.00, } \\
S D=0.073\end{array}$ \\
\hline Robbed & $\begin{array}{l}0.3 \%(27) \\
\text { Mean }=0.004 \\
S D=0.084\end{array}$ & $\begin{array}{l}0.3 \%(22) \\
\text { Mean }=0.00 \\
S D=0.073\end{array}$ \\
\hline Extorted & $\begin{array}{l}0.1 \%(7) \\
\text { Mean=0.00, } \\
S D=0.070\end{array}$ & $\begin{array}{l}0.1 \%(7) \\
\text { Mean=0.00, } \\
S D=0.029\end{array}$ \\
\hline Kidnapping & Not available & $\begin{array}{l}0.1 \%(5) \\
\text { Mean=0.00, } \\
S D=0.024\end{array}$ \\
\hline
\end{tabular}

by physical violence $(6.6 \%)$. Other less common forms of violence experienced included being falsely accused $(2.2 \%)$, bullied or harassed $(1.1 \%)$, being shown or attacked with weapon $(0.7 \%)$, damage to facility $(0.4 \%)$, being robbed $(0.3 \%)$, and being extorted $(0.1 \%)$.

Table 3 shows the predictors of violence against field HCWs who experienced violence. Work experience of 10 years and above was significantly related to experiencing less physical violence (adjusted $\mathrm{OR}=0.34 ; 95 \%$ CI 0.18 to $0.65 ; \mathrm{p}=0.001$ ) and verbal violence (adjusted $\mathrm{OR}=0.63$; $95 \%$ CI 0.46 to $0.88 ; \mathrm{p}=0.008$ ). Female field HCWs were significantly more likely to experience verbal violence (adjusted OR=1.56; 95\% CI 1.16 to 2.10; $\mathrm{p}=0.003$ ). Among the different types of field HCWs, emergency vehicle operators were significantly more likely to experience verbal violence with reference to LHWs (adjusted $\mathrm{OR}=1.97 ; 95 \%$ CI 1.31 to $2.94 ; \mathrm{p}=0.001$ ).

Table 4 shows the predictors of violence against tertiary care hospital HCWs in big cities who experienced violence. HCWs in private hospitals were significantly less likely to experience physical violence (adjusted OR $=0.52 ; 95 \%$ CI 0.38 to $0.71 ; \mathrm{p}=0.001$ ) and verbal violence (adjusted $\mathrm{OR}=0.57$; $95 \%$ CI 0.48 to 0.68 ; $\mathrm{p}=0.001$ ). With reference to HCWs in diagnostics, HCWs in emergency departments were significantly more likely to experience physical violence (adjusted $\mathrm{OR}=5.84 ; 95 \%$ CI 2.17 to $15.72 ; \mathrm{p}<0.001)$. Among the different types of HCWs, in comparison with administration staff, security guards were significantly more likely to experience verbal violence (adjusted $\mathrm{OR}=1.77 ; 95 \%$ CI 1.07 to 2.92; $\mathrm{p}=0.024)$.

Table 5 shows the predictors of violence against secondary care hospital HCWs in districts and tehsils who experienced violence. In comparison with private facilities, HCWs in government facilities were significantly more likely to experience verbal violence $(p<0.001)$. Among the different types of HCWs, in comparison with support staff, doctors were significantly less likely to experience physical violence (adjusted $\mathrm{OR}=0.56$; $95 \%$ CI 0.32 to $0.97 ; \mathrm{p}=0.039$ ) and more likely to experience verbal violence (adjusted $\mathrm{OR}=1.89 ; 95 \%$ CI 1.32 to 2.71 ; $\mathrm{p}=0.001$ ).

Table 6 shows the predictors of violence against HCWs in basic health units and private clinics who experienced violence. In comparison with private clinics, HCWs in basic health units were significantly more likely to experience verbal violence (adjusted $\mathrm{OR}=2.22 ; 95 \%$ CI 1.39 to $3.55 ; \mathrm{p}=0.001)$.

Figures 1 and 2 show the main reasons for physical and verbal violence, respectively. Among reasons for physical violence related to patient condition and outcome, death of the patient $(17.6 \%)$ and reaction to serious condition of the patient $(16.6 \%)$ were the two most important reasons. Among reasons related to quality of services, delay in care $(13.4 \%)$ was the most important reason, followed by complaints of poor care $(2.3 \%)$. Among reasons related to resources, lack of medicines or equipment was reported highly $(6.2 \%)$, followed by high workload due to high number of patients $(3.7 \%)$ and overcrowding due to high number of attendants $(3.4 \%)$. Among reasons related to patients' behaviour, reaction of attendants when stopped to limit access especially by security guards $(7.2 \%)$ was the most important, followed by misconception about vaccines reported highly by vaccinators and LHWs (6\%), impatience to wait for turn $(5.3 \%)$ and referral of the patient $(3.7 \%)$. Among psychosocial reasons, inability to pay was the main reason $(1.9 \%)$. Attendants were the chief perpetrators of the physical violence $(90.5 \%)$.

Among reasons for verbal violence related to quality of services, delay in care $(16.5 \%)$ was the most important reason, followed by complaints of poor care $(5.4 \%)$ and mistake in care $(1.5 \%)$. Among reasons related to patient condition and outcome, death of the patient $(3.1 \%)$ and reaction to serious condition of the patient $(4 \%)$ were the two most important reasons. Among reasons related to resources, lack of medicines or equipment was reported highly (10\%), followed by high workload due to high number of patients (7.2\%) and overcrowding due to high number of attendants $(7.6 \%)$. Among reasons related to patients' behaviour, misconception about vaccines reported highly by vaccinators and LHWs $(8.4 \%)$ was the main reason, followed by impatience to wait for 
Table 3 Predictors of violence against field healthcare workers who experienced violence $(n=2303)$

\begin{tabular}{|c|c|c|c|c|c|c|}
\hline & \multicolumn{2}{|c|}{ Any form of violence } & \multicolumn{2}{|c|}{ Physical violence } & \multicolumn{2}{|c|}{ Verbal violence } \\
\hline & $\begin{array}{l}\text { Adjusted OR } \\
(95 \% \mathrm{Cl})\end{array}$ & $P$ value & $\begin{array}{l}\text { Adjusted OR } \\
(95 \% \mathrm{Cl})\end{array}$ & $P$ value & $\begin{array}{l}\text { Adjusted OR } \\
(95 \% \mathrm{Cl})\end{array}$ & $P$ value \\
\hline \multicolumn{7}{|l|}{ Age } \\
\hline $18-29(n=875)$ & 1 & & 1 & & 1 & \\
\hline $30-44(n=1196)$ & 0.91 (0.70 to 1.17$)$ & 0.467 & 1.55 (0.95 to 2.53$)$ & 0.079 & 0.77 (0.59 to 1.01$)$ & 0.051 \\
\hline 45 and above (320) & 0.86 (0.58 to 1.26$)$ & 0.451 & 2.04 (0.92 to 4.53$)$ & 0.079 & 0.71 (0.47 to 1.08$)$ & 0.111 \\
\hline \multicolumn{7}{|l|}{ Work experience } \\
\hline $1-4$ years $(n=966)$ & 1 & & 1 & & 1 & \\
\hline $5-9$ years $(n=579)$ & 0.82 (0.63 to 1.07$)$ & 0.162 & 0.60 (0.35 to 1.01$)$ & 0.055 & 0.80 (0.61 to 1.05$)$ & 0.117 \\
\hline 10 years and above $(n=846)$ & 0.67 (0.47 to 0.89$)$ & 0.008 & 0.34 (0.18 to 0.65$)$ & 0.001 & $0.63(0.46$ to 0.88$)$ & 0.008 \\
\hline \multicolumn{7}{|l|}{ Gender } \\
\hline Male $(n=1260)$ & 1 & & 1 & & 1 & \\
\hline Female $(n=1131)$ & 1.57 (1.18 to 2.09$)$ & 0.002 & 1.01 (0.53 to 1.95$)$ & 0.955 & 1.56 (1.16 to 2.10$)$ & 0.003 \\
\hline \multicolumn{7}{|l|}{ Province } \\
\hline Punjab $(n=748)$ & 1 & & 1 & & 1 & \\
\hline Sindh $(n=760)$ & 2.31 (1.82 to 2.93$)$ & $<0.001$ & 3.00 (1.68 to 5.35$)$ & $<0.001$ & 2.25 (1.75 to 2.90$)$ & $<0.001$ \\
\hline Khyber Pakhtunkhwa $(n=706)$ & 2.38 (1.87 to 3.03 ) & $<0.001$ & 2.44 (1.35 to 4.40$)$ & 0.003 & 2.15 (1.67 to 2.76$)$ & $<0.001$ \\
\hline Islamabad $(n=177)$ & 0.52 (0.32 to 0.82$)$ & 0.006 & 0.83 (0.27 to 2.56$)$ & 0.759 & $0.36(0.21$ to 0.64$)$ & $<0.001$ \\
\hline \multicolumn{7}{|l|}{ Job title } \\
\hline LHW $(n=710)$ & 1 & & 1 & & 1 & \\
\hline EVO $(n=420)$ & 2.1 (1.42 to 3.09$)$ & $<0.001$ & 0.90 (0.38 to 2.09$)$ & 0.807 & 1.97 (1.31 to 2.94$)$ & 0.001 \\
\hline Vaccinator $(n=924)$ & 1.25 (0.94 to 1.66$)$ & 0.125 & 0.58 (0.31 to 1.10$)$ & 0.097 & $1.20(0.90$ to 1.62$)$ & 0.204 \\
\hline EMT $(n=249)$ & 1.25 (0.81 to 1.94$)$ & 0.305 & 1.05 (0.42 to 2.57$)$ & 0.912 & 1.09 (0.68 to 1.72$)$ & 0.711 \\
\hline \multicolumn{7}{|l|}{ Security index } \\
\hline Low $(n=795)$ & 1 & & 1 & & 1 & \\
\hline Moderate (801) & 0.94 (0.75 to 1.18$)$ & 0.619 & 0.75 (0.47 to 1.19$)$ & 0.225 & $1.00(0.79$ to 1.26$)$ & 0.979 \\
\hline High (795) & 0.96 (0.76 to 1.20$)$ & 0.749 & $0.76(0.48$ to 1.21$)$ & 0.255 & 1.11 (0.88 to 1.41$)$ & 0.352 \\
\hline
\end{tabular}

EMT, emergency medical technician; EVO, emergency vehicle operator; LHW, lady health worker.

turn $(5.4 \%)$, demand of care of personal choice $(4.8 \%)$, demand of protocol $(4.5 \%)$ and referral of the patient $(2.4 \%)$. Among psychosocial reasons, inability to pay was the main reason $(2.2 \%)$. Among professional reasons, dissatisfaction of senior with job performance $(1.5 \%)$ and being late or absent from duty (1.5\%) were the two main reasons for verbal violence. Attendants (79\%) followed by patients $(13.4 \%)$ were the chief perpetrators of the verbal violence.

More than two-thirds $(70.5 \%)$ reported the event if they experienced any violence $(n=3300)$. Among those who reported the incident $(n=2328)$, the majority reported to their senior $(38.6 \%)$, security in charge $(34.8 \%)$ or management of their organisation $(23.2 \%)$. As a result of reporting, almost half were investigated $(43.4 \%)$, while there was no response in the case of one-third of events reported $(34.1 \%)$. Among those who did not report, the majority considered it useless $(73.6 \%)$, while some of them were afraid of the negative consequences $(14.5 \%)$.

\section{DISCUSSION}

This is one of the very few studies on violence against HCWs which has been conducted on such a large scale involving data gathering from multiple cadres of HCWs from 16 districts in 3 provinces of a country.

On average each HCW experienced 4.15 events of violence, with more than one-third reporting having experienced any form of violence in the last 6 months. Verbal violence was the most commonly experienced form $(33.9 \%)$, followed by physical violence $(6.6 \%)$. Since these are combined estimates of all cadres of HCWs, our comparisons will be based on different cadres of HCWs that other studies have focused on. These findings are strikingly similar to the study done in Karachi on similar cadres of HCWs, where $30.5 \%$ reported verbal while $14.6 \%$ revealed having experienced physical violence. ${ }^{20}$ The lower frequency of physical violence reported in this study could be due to a shorter recall period of 6 months as compared with the 1-year recall used by most studies. 
Table 4 Predictors of violence against healthcare workers in tertiary care hospitals who experienced violence $(n=2815)$

\begin{tabular}{|c|c|c|c|c|c|c|}
\hline & \multicolumn{2}{|c|}{ Any form of violence } & \multicolumn{2}{|c|}{ Physical violence } & \multicolumn{2}{|c|}{ Verbal violence } \\
\hline & $\begin{array}{l}\text { Adjusted OR } \\
(95 \% \mathrm{Cl})\end{array}$ & $P$ value & $\begin{array}{l}\text { Adjusted OR } \\
(95 \% \mathrm{Cl})\end{array}$ & $P$ value & $\begin{array}{l}\text { Adjusted OR } \\
(95 \% \mathrm{Cl})\end{array}$ & $P$ value \\
\hline \multicolumn{7}{|l|}{ Age } \\
\hline $18-29(n=1511)$ & 1 & & 1 & & 1 & \\
\hline $30-44(n=1054)$ & $1.05(0.86$ to 1.28$)$ & 0.61 & $1.28(0.92$ to 1.80$)$ & 0.136 & 1.00 (0.82 to 1.22$)$ & 0.61 \\
\hline 45 and above (250) & $1.33(0.93$ to 1.89$)$ & 0.114 & 1.20 (0.67 to 2.14$)$ & 0.52 & 1.33 (0.93 to 1.90$)$ & 0.111 \\
\hline \multicolumn{7}{|l|}{ Work experience } \\
\hline $1-4$ years $(n=1730)$ & 1 & & 1 & & 1 & \\
\hline $5-9$ years $(n=503)$ & 1.04 (0.83 to 1.31$)$ & 0.692 & 1.18 (0.80 to 1.73$)$ & 0.4 & 1.01 (0.80 to 1.27$)$ & 0.904 \\
\hline 10 years and above $(n=582)$ & 0.91 (0.70 to 1.18$)$ & 0.496 & $1.10(0.72$ to 1.68$)$ & 0.655 & 0.84 (0.65 to 1.10$)$ & 0.22 \\
\hline \multicolumn{7}{|l|}{ Gender } \\
\hline Male $(n=1582)$ & 1 & & 1 & & 1 & \\
\hline Female $(n=1233)$ & 0.99 (0.82 to 1.18$)$ & 0.918 & 0.77 (0.55 to 1.07$)$ & 0.126 & 1.01 (0.84 to 1.22$)$ & 0.851 \\
\hline \multicolumn{7}{|l|}{ City } \\
\hline Lahore (n=722) & 1 & & 1 & & 1 & \\
\hline Karachi $(n=737)$ & 3.25 (2.52 to 4.18$)$ & $<0.001$ & 2.61 (1.63 to 4.18$)$ & $<0.001$ & 3.38 (2.61 to 4.37$)$ & $<0.001$ \\
\hline Peshawar $(n=627)$ & 2.16 (1.64 to 2.83$)$ & $<0.001$ & 2.00 (1.20 to 3.36$)$ & 0.008 & 2.07 (1.57 to 2.74$)$ & $<0.001$ \\
\hline Islamabad (n=729) & 2.47 (1.95 to 3.13 ) & $<0.001$ & 1.57 (0.98 to 2.51$)$ & 0.057 & 2.53 (1.99 to 3.22$)$ & $<0.001$ \\
\hline \multicolumn{7}{|l|}{ Type of hospital } \\
\hline Public $(n=1414)$ & 1 & & & & 1 & \\
\hline Private $(\mathrm{n}=1401)$ & 0.55 (0.46 to 0.65$)$ & $<0.001$ & 0.52 (0.38 to 0.71$)$ & $<0.001$ & 0.57 (0.48 to 0.68$)$ & $<0.001$ \\
\hline \multicolumn{7}{|l|}{ Department } \\
\hline Diagnostics $(n=252)$ & 1 & & & & 1 & \\
\hline Medicine and allied ( $n=619)$ & $1.25(0.84$ to 1.85$)$ & 0.255 & 3.00 (1.10 to 8.18$)$ & 0.032 & 1.03 (0.70 to 1.54$)$ & 0.849 \\
\hline Surgery and allied (n=634) & $1.00(0.69$ to 1.47$)$ & 0.966 & 3.29 (1.23 to 8.81$)$ & 0.018 & 0.91 (0.62 to 1.33$)$ & 0.631 \\
\hline Paediatrics $(n=427)$ & 1.30 (0.86 to 1.95$)$ & 0.205 & 3.26 (1.17 to 9.09$)$ & 0.023 & 1.07 (0.71 to 1.62$)$ & 0.735 \\
\hline $\begin{array}{l}\text { Gynaecology and obstetrics } \\
(n=406)\end{array}$ & 1.15 (0.76 to 1.73$)$ & 0.5 & 3.02 (1.07 to 8.54$)$ & 0.036 & 1.00 (0.66 to 1.52$)$ & 0.974 \\
\hline Emergency $(n=477)$ & 1.81 (1.22 to 2.69$)$ & 0.003 & 5.84 (2.17 to 15.72$)$ & $<0.001$ & 1.39 (0.93 to 2.08$)$ & 0.103 \\
\hline \multicolumn{7}{|l|}{ Job title } \\
\hline Administration $(n=137)$ & 1 & & 1 & & 1 & \\
\hline Intern/resident $(n=475)$ & 0.94 (0.61 to 1.44$)$ & 0.777 & 0.72 (0.35 to 1.45$)$ & 0.364 & 1.06 (0.68 to 1.65$)$ & 0.787 \\
\hline Medical officer $(n=569)$ & 0.78 (0.52 to 1.18$)$ & 0.25 & 0.54 (0.28 to 1.04$)$ & 0.066 & 0.86 (0.56 to 1.31$)$ & 0.496 \\
\hline Consultant (n=131) & 1.00 (0.58 to 1.70$)$ & 1 & 0.80 (0.34 to 1.89$)$ & 0.618 & 1.27 (0.74 to 2.19$)$ & 0.374 \\
\hline Nurse $(n=602)$ & 1.03 (0.68 to 1.55$)$ & 0.873 & 0.54 (0.27 to 1.05$)$ & 0.071 & 1.21 (0.79 to 1.84$)$ & 0.374 \\
\hline Technician $(\mathrm{n}=566)$ & 1.05 (0.69 to 1.61$)$ & 0.802 & 0.68 (0.35 to 1.33$)$ & 0.263 & 1.12 (0.72 to 1.73$)$ & 0.6 \\
\hline Housekeeping staff $(n=180)$ & 1.09 (0.67 to 1.76$)$ & 0.711 & 0.80 (0.38 to 1.69$)$ & 0.571 & 1.04 (0.64 to 1.70$)$ & 0.859 \\
\hline Security guard (n=155) & 1.96 (1.19 to 3.21$)$ & 0.008 & 1.84 (0.93 to 3.64$)$ & 0.078 & 1.77 (1.07 to 2.92$)$ & 0.024 \\
\hline \multicolumn{7}{|l|}{ Security index } \\
\hline Low (n=242) & 1 & & 1 & & 1 & \\
\hline Moderate $(n=736)$ & 1.24 (0.90 to 1.70$)$ & 0.174 & 1.04 (0.63 to 1.74$)$ & 0.856 & 1.19 (0.86 to 1.64$)$ & 0.277 \\
\hline High $(n=1837)$ & 1.26 (0.91 to 1.74$)$ & 0.155 & 1.09 (0.65 to 1.84$)$ & 0.731 & $1.28(0.92$ to 1.77$)$ & 0.131 \\
\hline
\end{tabular}


Table 5 Predictors of violence against healthcare workers in secondary care hospitals who experienced violence $(n=1928)$

\begin{tabular}{|c|c|c|c|c|c|c|}
\hline & \multicolumn{2}{|c|}{ Any form of violence } & \multicolumn{2}{|l|}{ Physical violence } & \multicolumn{2}{|l|}{ Verbal violence } \\
\hline & $\begin{array}{l}\text { Adjusted OR } \\
(95 \% \mathrm{Cl})\end{array}$ & $P$ value & $\begin{array}{l}\text { Adjusted OR } \\
(95 \% \mathrm{Cl})\end{array}$ & $P$ value & $\begin{array}{l}\text { Adjusted OR } \\
(95 \% \mathrm{Cl})\end{array}$ & $P$ value \\
\hline \multicolumn{7}{|l|}{ Age } \\
\hline $18-29(n=726)$ & 1 & & 1 & & 1 & \\
\hline $30-44(n=897)$ & 0.96 (0.74 to 1.24$)$ & 0.781 & 1.26 (0.77 to 2.05$)$ & 0.35 & 1.08 (0.83 to 1.41$)$ & 0.541 \\
\hline 45 and above (305) & $1.15(0.77$ to 1.71$)$ & 0.492 & 1.01 (0.48 to 2.11$)$ & 0.97 & 1.26 (0.84 to 1.90$)$ & 0.255 \\
\hline \multicolumn{7}{|l|}{ Work experience } \\
\hline $1-4$ years $(n=792)$ & 1 & & 1 & & 1 & \\
\hline $5-9$ years $(n=536)$ & 1.31 (1.01 to 1.70$)$ & 0.039 & 1.50 (0.92 to 2.45$)$ & 0.099 & 1.21 (0.93 to 1.57$)$ & 0.152 \\
\hline 10 years and above $(n=600)$ & 1.00 (0.72 to 1.39$)$ & 0.973 & 1.12 (0.62 to 2.04$)$ & 0.699 & 0.78 (0.56 to 1.09$)$ & 0.151 \\
\hline \multicolumn{7}{|l|}{ Gender } \\
\hline Male $(n=1341)$ & 1 & & 1 & & 1 & \\
\hline Female $(n=587)$ & 0.96 (0.73 to 1.26$)$ & 0.801 & 0.77 (0.47 to 1.26$)$ & 0.306 & 0.99 (0.75 to 1.31$)$ & 0.992 \\
\hline \multicolumn{7}{|l|}{ City } \\
\hline Punjab ( $n=689)$ & 1 & & 1 & & 1 & \\
\hline Sindh $(n=579)$ & 0.53 (0.41 to 0.68$)$ & $<0.001$ & 2.47 (1.60 to 3.83 ) & $<0.001$ & 0.59 (0.46 to 0.76$)$ & $<0.001$ \\
\hline Khyber Pakhtunkhwa $(n=660)$ & 0.68 (0.53 to 0.89$)$ & 0.005 & 0.63 (0.36 to 1.10$)$ & 0.107 & 0.78 (0.60 to 1.02$)$ & 0.07 \\
\hline \multicolumn{7}{|l|}{ Type of hospital } \\
\hline Private hospital $(n=950)$ & 1 & & 1 & & 1 & \\
\hline $\begin{array}{l}\text { District headquarter hospital } \\
(\mathrm{n}=448)\end{array}$ & 1.93 (1.52 to 2.45$)$ & $<0.001$ & 1.52 (0.97 to 2.38$)$ & 0.062 & 2.08 (1.63 to 2.64$)$ & $<0.001$ \\
\hline $\begin{array}{l}\text { Tehsil headquarter hospital } \\
(n=530)\end{array}$ & 1.58 (1.26 to 2.00$)$ & $<0.001$ & 1.99 (1.30 to 3.05$)$ & 0.001 & 1.65 (1.31 to 2.09 ) & $<0.001$ \\
\hline \multicolumn{7}{|l|}{ Department } \\
\hline Diagnostics $(n=221)$ & 1 & & & & 1 & \\
\hline Emergency $(\mathrm{n}=270)$ & 2.28 (1.49 to 3.50$)$ & $<0.001$ & 2.77 (1.16 to 6.61$)$ & 0.022 & 2.01 (1.30 to 3.09 ) & 0.001 \\
\hline Medicine and allied $(n=537)$ & 1.09 (0.74 to 1.61$)$ & 0.631 & 1.23 (0.51 to 2.95$)$ & 0.634 & 0.96 (0.64 to 1.42$)$ & 0.843 \\
\hline Surgery and allied $(n=401)$ & 0.83 (0.56 to 1.23$)$ & 0.374 & 1.30 (0.55 to 3.10$)$ & 0.543 & 0.75 (0.50 to 1.12 ) & 0.169 \\
\hline Paediatrics $(n=247)$ & 1.76 (1.14 to 2.72$)$ & 0.011 & 1.66 (0.66 to 4.17$)$ & 0.281 & 1.52 (0.98 to 2.37$)$ & 0.059 \\
\hline $\begin{array}{l}\text { Gynaecology and obstetrics } \\
(n=252)\end{array}$ & 1.57 (1.00 to 2.49$)$ & 0.05 & 1.14 (0.43 to 3.02$)$ & 0.791 & 1.30 (0.82 to 2.06$)$ & 0.264 \\
\hline \multicolumn{7}{|l|}{ Job title } \\
\hline Support staff (n=178) & 1 & & 1 & & 1 & \\
\hline Doctor (741) & 1.35 (0.96 to 1.91$)$ & 0.083 & 0.56 (0.32 to 0.97$)$ & 0.039 & 1.89 (1.32 to 2.71$)$ & 0.001 \\
\hline Nurse $(n=501)$ & 1.24 (0.84 to 1.84$)$ & 0.268 & 0.57 (0.30 to 1.09$)$ & 0.09 & 1.53 (1.02 to 2.30$)$ & 0.04 \\
\hline Technician $(n=508)$ & 0.97 (0.66 to 1.43$)$ & 0.898 & $0.43(0.22$ to 0.81$)$ & 0.009 & 1.31 (0.88 to 1.96$)$ & 0.18 \\
\hline \multicolumn{7}{|l|}{ Security index } \\
\hline Low $(n=841)$ & 1 & & 1 & & 1 & \\
\hline Moderate (n=919) & 1.07 (0.86 to 1.33$)$ & 0.515 & 0.84 (0.56 to 1.25$)$ & 0.41 & 1.19 (0.95 to 1.48$)$ & 0.119 \\
\hline High $(n=168)$ & 1.52 (1.04 to 2.22$)$ & 0.03 & 1.20 (0.62 to 2.32 ) & 0.587 & 1.73 (1.18 to 2.54$)$ & 0.005 \\
\hline
\end{tabular}

Recall period of 6 months in this study was used to quantify the average number of events.

Among hospital-based workers, $35.4 \%$ experienced verbal while $7.1 \%$ experienced physical violence. These findings are similar to a national survey among hospitalbased workers in Turkey which reports verbal violence experienced by $43.2 \%$ and physical violence by $6.8 \%$ HCWs. ${ }^{21}$ However, large-scale surveys in Congo, Palestine and Iraq report overall violence experienced by hospital-based HCWs ranging from $80.4 \%$ to $85 \%$. ${ }^{622} 23$ One possible reason for the extremely high frequencies in these countries could be the effect of conflicts in these 
Table 6 Predictors of violence against healthcare workers in basic health units and private clinics who experienced violence $(n=628)$

\begin{tabular}{|c|c|c|c|c|c|c|}
\hline & \multicolumn{2}{|c|}{ Any form of violence } & \multicolumn{2}{|l|}{ Physical violence } & \multicolumn{2}{|l|}{ Verbal violence } \\
\hline & $\begin{array}{l}\text { Adjusted OR } \\
(95 \% \mathrm{Cl})\end{array}$ & $P$ value & $\begin{array}{l}\text { Adjusted OR } \\
(95 \% \mathrm{Cl})\end{array}$ & $P$ value & $\begin{array}{l}\text { Adjusted OR } \\
(95 \% \mathrm{Cl})\end{array}$ & $P$ value \\
\hline \multicolumn{7}{|l|}{ Age } \\
\hline $18-29(n=163)$ & 1 & & 1 & & 1 & \\
\hline $30-44(n=312)$ & $1.21(0.70$ to 2.11$)$ & 0.479 & 1.66 (0.48 to 5.67$)$ & 0.419 & $1.16(0.64$ to 2.11$)$ & 0.609 \\
\hline 45 and above $(n=153)$ & 1.85 (0.88 to 3.87 ) & 0.102 & 0.32 (0.04 to 2.33 ) & 0.261 & 2.72 (1.21 to 6.09$)$ & 0.015 \\
\hline \multicolumn{7}{|l|}{ Work experience } \\
\hline $1-4$ years $(n=219)$ & 1 & & 1 & & & \\
\hline $5-9$ years $(n=149)$ & 1.03 (0.59 to 1.78$)$ & 0.907 & $1.06(0.34$ to 3.29$)$ & 0.917 & 1 & \\
\hline 10 years and above $(n=260)$ & 1.04 (0.57 to 1.90$)$ & 0.882 & $1.48(0.44$ to 4.99$)$ & 0.523 & 0.85 (0.47 to 1.55$)$ & 0.614 \\
\hline \multicolumn{7}{|l|}{ Gender } \\
\hline Male $(n=497)$ & 1 & & 1 & & 1 & \\
\hline Female $(n=131)$ & 1.38 (0.86 to 2.19$)$ & 0.172 & 0.77 (0.36 to 2.27$)$ & 0.642 & 1.38 (0.84 to 2.19$)$ & 0.198 \\
\hline \multicolumn{7}{|l|}{ Province } \\
\hline Punjab $(n=163)$ & 1 & & 1 & & 1 & \\
\hline Sindh $(n=300)$ & 0.86 (0.49 to 1.30$)$ & 0.379 & $0.56(0.19$ to 1.67$)$ & 0.301 & 0.91 (0.53 to 1.54$)$ & 0.729 \\
\hline Khyber Pakhtunkhwa $(n=165)$ & 1.43 (0.86 to 2.39$)$ & 0.16 & 0.87 (0.30 to 2.47$)$ & 0.795 & 1.48 (0.85 to 2.58$)$ & 0.166 \\
\hline \multicolumn{7}{|l|}{ Type of workplace } \\
\hline Private clinic $(n=293)$ & 1 & & 1 & & 1 & \\
\hline Basic health unit $(n=335)$ & 2.55 (1.66 to 3.91$)$ & $<0.001$ & 2.25 (0.83 to 6.12$)$ & 0.109 & 2.22 (1.39 to 3.55$)$ & 0.001 \\
\hline \multicolumn{7}{|l|}{ Job title } \\
\hline Support staff $(n=113)$ & 1 & & 1 & & 1 & \\
\hline Doctor (393) & 1.04 (0.62 to 1.74$)$ & 0.881 & $1.28(0.44$ to 3.70$)$ & 0.648 & $1.17(0.65$ to 2.10$)$ & 0.594 \\
\hline Nurse $(n=62)$ & 1.37 (0.59 to 3.16$)$ & 0.459 & 0.00 (0.00 to 0.00$)$ & $\begin{array}{l}\text { Not } \\
\text { applicable }\end{array}$ & 1.97 (0.79 to 4.86$)$ & 0.141 \\
\hline Technician $(n=60)$ & 0.96 (0.46 to 2.02$)$ & 0.926 & $0.32(0.03$ to 2.90$)$ & 0.313 & 1.31 (0.58 to 2.94$)$ & 0.514 \\
\hline
\end{tabular}

countries. Among the factors that influenced experience of violence in primary, secondary and tertiary care hospitals in this study, age, work experience and gender had no significant effect on experiencing violence in this study. Similarly, no trends were observed for work experience and violence in this study, which is consistent

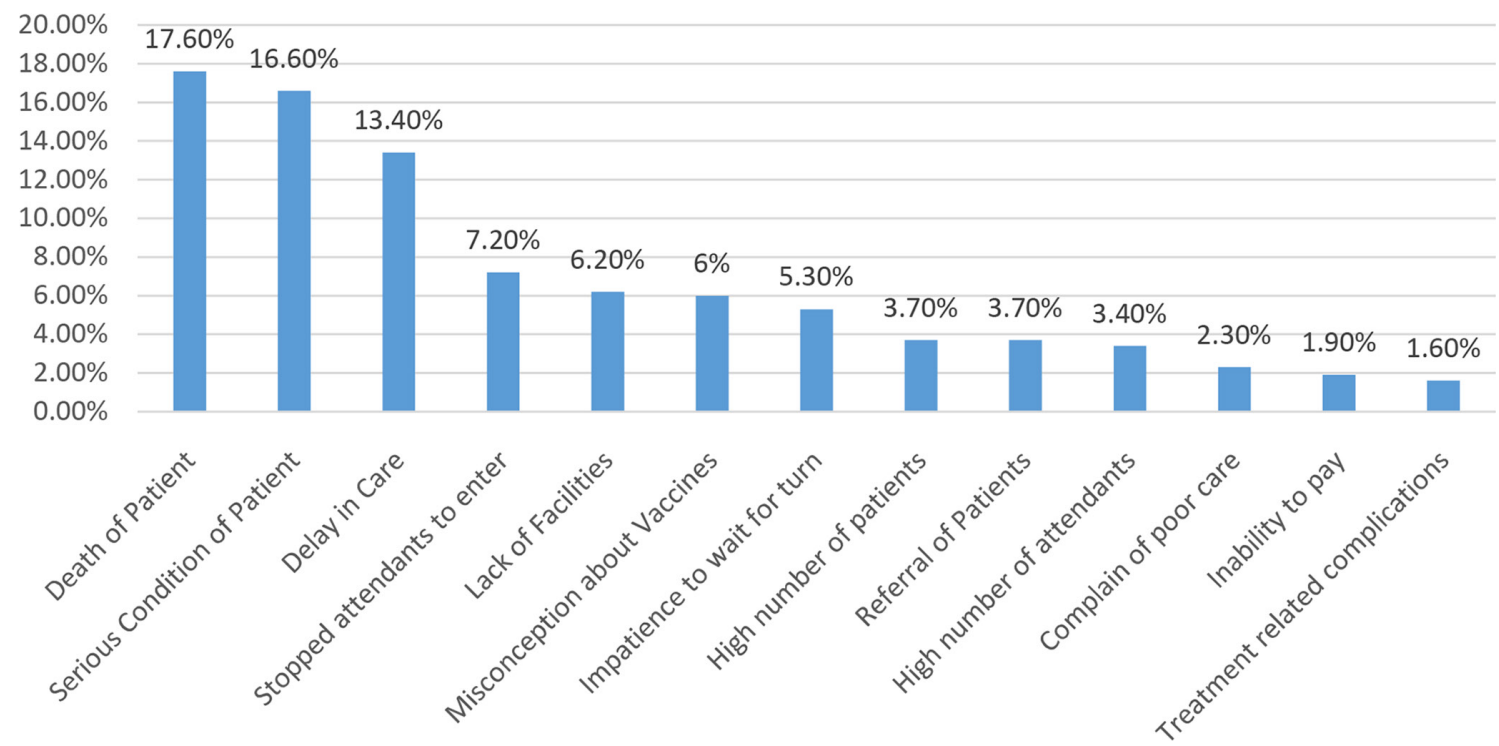

Figure 1 Reasons for physical violence experienced $(n=567)$. 


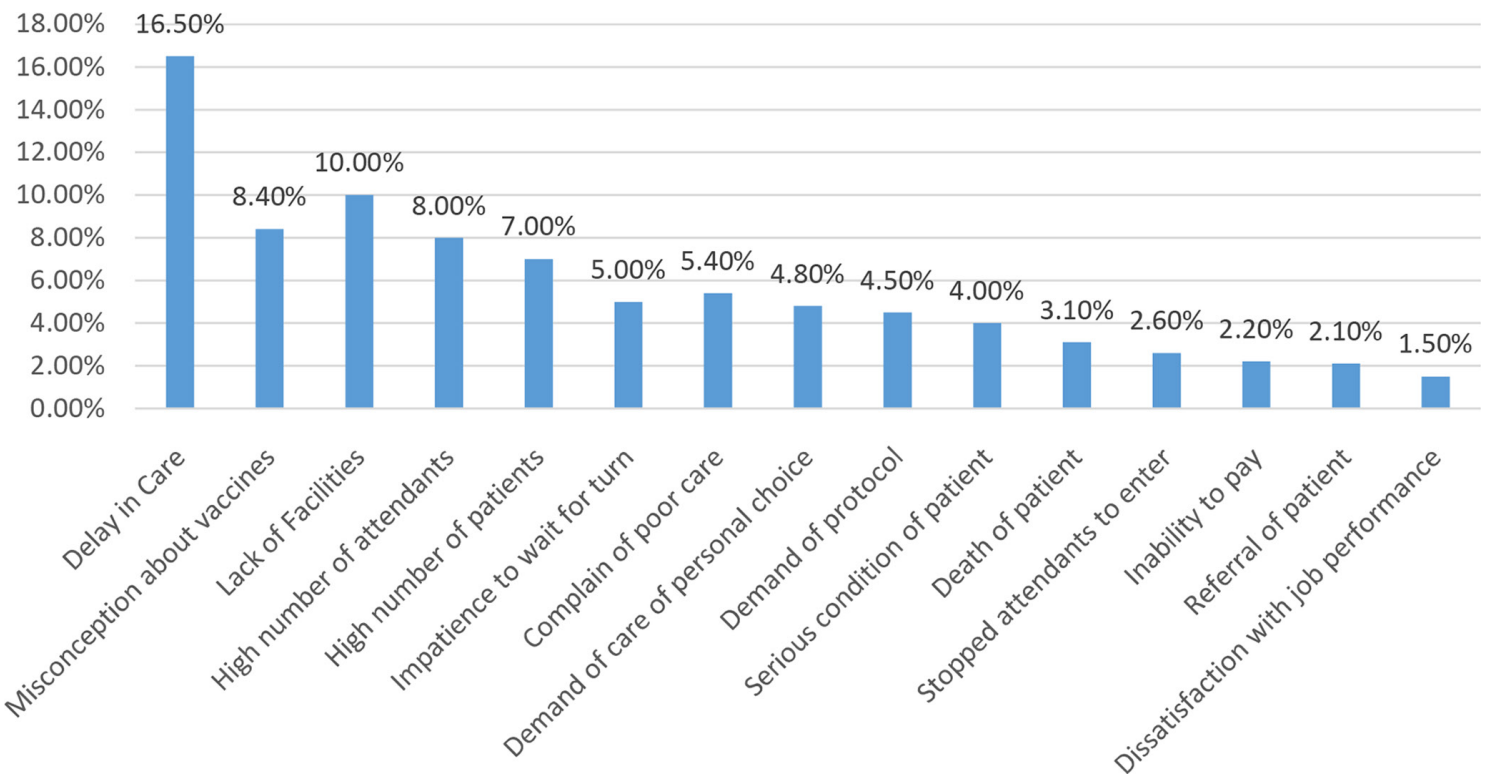

Figure 2 Reasons for verbal violence experienced ( $n=2909)$.

with a national survey in Turkey. ${ }^{21}$ Lack of significant association of gender and work experience in this study reflects that it is the institutional factors in hospitals that influence the experience of violence more than personal factors. In tertiary care hospitals, HCWs in big cities of other provinces were significantly more likely to experience violence as compared with the big city of Punjab (Lahore). This can be explained by the fact that Punjab, being a very large province, has less burden of patients in its major city Lahore, and the distribution of patients is more uniform than the other two provinces. At the primary healthcare level no significant difference was observed between provinces because utilisation and patient burden are relatively similar across provinces. HCWs in private hospitals were significantly less likely to experience physical as well as verbal violence in tertiary, secondary and primary hospitals. This finding is consistent with other studies, including the national surveys in Turkey and Taiwan. ${ }^{2124}$ It is observed that public hospitals are more overcrowded and under-resourced in comparison with private hospitals; therefore, they are also more likely to face violence. Among the different departments of hospitals, emergency departments were significantly more likely to experience physical as well as verbal violence in both secondary and tertiary care hospitals, while the chance of occurrence was uniformly distributed between other departments. This finding is also consistent with previous studies in hospitals of Italy, China, Bangladesh and Ethiopia. ${ }^{25-28}$ Among the different types of HCWs, in comparison with administration staff, security guards were significantly more likely to experience verbal violence in tertiary care hospitals, while the chance of occurrence was uniformly distributed between doctors, nurses and technicians. Understandably, guards are the first point of contact, which puts them at higher risk.
Among the fieldworkers, female HCWs were significantly more likely to experience verbal violence. While studies for comparisons in field health workers are not available, significant association of gender is indicative of different dynamics of fieldwork, where social factors tend to contribute along with institutional factors. The higher frequency of violence among women may be explained by the lack of acceptance and respect for women to do fieldwork in the society. Among the different types of field HCWs, emergency vehicle operators were significantly more likely to experience verbal violence with reference to LHWs. This is understandable as this is the group that mostly is the first point of contact dealing with medical emergencies.

Understandably, attendants were the chief perpetrators of all forms of violence, ranging from $67.7 \%$ to $90.5 \%$, followed by patients, ranging from $6.7 \%$ to $14.4 \%$. Peerperpetrated violence accounted for $1.2 \%-13.2 \%$ of the different forms of violence. This is consistent with previous literature in which attendants have been reported as chief perpetrators, accounting for $71.7 \%-94.9 \%$ of violence against $\mathrm{HCWs},{ }^{29}$ while peer-perpetrated violence ranged from $5.1 \%$ to $14.3 \% .^{3031}$

Based on the reasons reported by the HCWs in this study, they may be categorised into reasons related to patient condition and outcome, reasons related to quality of services, reasons related to resources, reasons related to patients' behaviour, job-related reasons and psychosocial reasons, although the categories can be crosscutting as many interacting factors together encompass violence. ${ }^{32}$ In primary, secondary care and tertiary care hospitals, the main reasons related to patient condition and outcome included death of the patient and serious condition. Therefore, it is important to work on HCWs' skills in emergency communication, including breaking bad news and de-escalation of aggressive behaviour, 
Table 7 Interventions to prevent violence against HCWs in hospitals

Reasons

Interventions

Potential to reduce the events

\title{
For HCWs in hospitals
}

Reaction to patient condition:

- Death.

- Serious condition.

- Treatment-related complication.

\section{Quality of care: \\ - Delay in care. \\ - Poor care.}

For HCWs in hospitals
Reaction to patient condition:
Death.
Serious condition.
Qreatment-related complication.
Quality of care:
Delay in care.
Poor care.

Lack of resources:

- Drugs, equipment, beds.

- Human resources.

\author{
Patient behaviour: \\ - Overcrowding. \\ - Impatience to wait. \\ - Demand of care of personal \\ choice. \\ - Expectation of protocol. \\ - Referral.
}

Job-related reasons:

- Dissatisfaction with job performance.

Training of HCWs in:

- Emergency care.

- Emergency communication.

- De-escalation skills.

\section{Training of HCWs in:}

- Improving responsiveness towards patients.

Policies on:

- Minimum response and waiting time.

- Information on waiting time.

- HCW performance assessment on behaviour, promptness of response, consultation time and quality of care.

- Complaint counters for clients.

Policies on:

- Patient to HCW ratio.

- Availability of medicines, supplies and equipment based on service delivery standards for level of care and distribution of disease burden.

Educational measures:

- Awareness campaigns on the importance of one attendant policy, waiting for their turn and following the instructions of HCWs related to treatment, admission and care.

- Awareness and information about referral.

Regulatory measures:

- Adherence to access restriction policies of hospitals.

- Making assault a non-bailable offence.

- Zero tolerance policy at organisational level.

- Grievance policies for junior-level staff.
$15 \%$ verbal violence.

$30 \%$ of physical violence.

$20 \%$ of physical violence. $25 \%$ verbal violence.

$10 \%$ physical violence. $25 \%$ verbal violence.

$20 \%$ physical violence. $30 \%$ verbal violence.

$2.5 \%$ physical violence. $4 \%$ verbal violence.

- Disagreeing on job conditions.

- Being late or absent.

For HCWs in ambulance services

Reaction to patient condition:

$\checkmark$ Death.

- Serious condition.

- Treatment-related complication.

Quality of care:

- Delay in arrival and shifting the patient.

- Poor care.

\section{Lack of resources:}

- Equipment in ambulances for provision of standard prehospital emergency care.

Patient behaviour:

- Demand of care of personal choice.

- Demand of speeding up ambulance.

- Expectation of protocol.

Job-related reasons:

- Dissatisfaction with job performance.

- Disagreeing on job conditions.

- Being late or absent.
Training of HCWs in:

- Emergency care.

- Emergency communication.

- De-escalation skills.

Training of paramedics on:

- Emergency care and shifting of the patient.

Policies on:

- Minimum response time.

- Information on waiting time.

- Upscaling services based on burden.

- Financial investment to equip ambulance services and set prehospital emergency care standards.

\section{Educational measures:}

- Awareness campaigns on the importance of following the instructions of HCWs.

Regulatory measures:

- Making assault a non-bailable offence.

- Zero tolerance policy at organisational level.

- Grievance policies for junior-level staff.
$10 \%$ physical violence.

$10 \%$ verbal violence.

$10 \%$ verbal violence.

$30 \%$ of physical violence.

$45 \%$ of physical violence. $50 \%$ verbal violence.

$10 \%$ physical violence. $25 \%$ verbal violence. $5 \%$ verbal violence.
$5 \%$ physical violence.

For LHWs and vaccinators 


\begin{tabular}{lll}
\hline Reasons & Interventions & Potential to reduce the \\
events
\end{tabular}

HCWs, healthcare workers; LHWs, lady health workers; MNCH, Maternal Neonatal and Child Health.

which has great potential for averting more severe forms of violence against them. Interventional studies in which HCWs have been trained in communication and de-escalation skills have shown significant reduction in perceived patient aggression and improvement in coping with patient aggression. ${ }^{33} 34$ The main reasons related to quality of services include delay in care (medication, procedure, attending patient, long waiting time, shifting patient and starting treatment) and complaints of poor care (medication, dosage, handling of patient, behaviour of doctor). In terms of diagnostic departments, delay in reporting and wrong reporting were highlighted the most. Therefore, it is important to train HCWs in maintaining dignity, confidentiality, autonomy and respectful communication. Policies on minimum response and waiting times and informing the patients/attendants about the time required to initiate the treatment need to be introduced. The performance of HCWs should also be periodically reviewed based on his/her behaviour, timely response, consultation time and quality of care. Reasons related to lack of resources include lack of facilities and human resources. It is imperative to introduce standards on patient to HCW ratios and staff the facilities based on patient volume in the hospital. The availability of medicines, supplies and equipment should be based on determined service delivery standards for level of care and distribution of disease burden. Reasons related to patient behaviour include overcrowding due to high number of attendants, stopping attendants to limit their access, impatience to wait for turn and demand of care of personal choice (doctor, medicine, admission, procedure, home care). These require educational as well as regulatory measures. Educational measures include awareness campaigns on the importance of one attendant policy, waiting for their turn and following the instructions of HCWs related to treatment, admission and care.
An interventional study from Iran which focused on patient education has reported reduction in the events of violence by $18.6 \% .^{35}$ Regulatory measures include adherence to access restriction policies of hospitals. Job-related reasons perpetrated by colleagues or seniors included dissatisfaction with performance, being late or disagreeing on job conditions. However, these reasons only accounted for up to $2.5 \%$ of physical violence and $4 \%$ of verbal violence, possibly because they are likely to be under-reported as well. The way forward to deal with this kind of peer violence would be to introduce grievance policies for junior-level staff and zero tolerance policy at the organisational level so that all matters are resolved through respectful communication rather than resorting to any form of violence.

Among ambulance workers, specific reasons included late arrival of ambulance, delay in shifting the patient and complaints of poor care. This is indicative of insufficient ambulance services which are not at par with the volume of services needed and standards of emergency care. Therefore, it is imperative that the needed services are estimated based on the burden of patients, and standards of maximum response time should be set. Moreover, skilled paramedics ensuring the promptness and safety while shifting the patients and providing them standard emergency care would strengthen the confidence of the attendants in the services.

Dominant reasons among LHWs and vaccinators were related to behaviour of clients. The most frequently reported was misconception about vaccines, followed by misconception about family planning, referral of the patient and complaints of repeated visits by clients. While there have been many attempts of awareness intervention in changing the perceptions of people regarding vaccination and family planning, there is a need to revise the strategy to accommodate the concerns of people 
and build national consensus on existing controversies related to these services.

\section{Study limitations}

The main limitation in this study is that the number of clusters required for the calculated sample size was not statistically determined. Instead, the number of cities to be taken from each province was conveniently determined due to limited resources. Moreover, the province of Baluchistan, northern areas of Gilgit Baltistan, tribal areas in Khyber Pakhtunkhwa and areas from Azad Jammu \& Kasmir have not been included mainly due to limited resources and partly due to security concerns. Still, inclusion of four districts from different regions within each province and the provincial capital provides good evidence of the overall larger picture within the provinces. Second, in response-based studies, there is always a chance of under-reporting and over-reporting bias. Moreover, there is also a wish bias in which respondents tend to perceive a certain situation through their own lens. Third, some of the risk factors identified in the literature have not been covered in this study. Working in shifts showed positive association with experiencing violence in a nationwide survey on nurses in Lebanon. ${ }^{36}$ In another study in China, low empathy levels showed positive association with experiencing violence. ${ }^{37}$ It is however practically very difficult to include variables requiring data on multiple items in an extremely largescale survey, which requires training many data collectors.

\section{Way forward}

As classified in the analysis, we propose interventions according to the reason and the potential of these interventions to reduce the incidents of violence. Table 7 summarises the interventions for hospital workers, ambulance workers and LHWs and vaccinators. Based on the findings of the report, the following recommendations are being made:

- There is a need to train HCWs in skills in emergency communication and skills to de-escalate violence. It is also important to apprise them of maintaining dignity, confidentiality, autonomy and respectful communication with patients and attendants.

- Policies on minimum response and waiting time and informing the patients/attendants about the time required to initiate the treatment need to be introduced. Grievance-redressal policies for staff and a zero tolerance policy for addressing violence at the organisational level should also be introduced in all healthcare organisations.

- Standards on patient to HCW ratios need to be introduced and facilities should be staffed based on patient volume in the hospital.

- The availability of medicines, supplies and equipment should be ensured based on determined service delivery standards for level of care and distribution of disease burden.
- There is a need to ensure adequate security resources and infrastructure at healthcare facilities for protection of healthcare.

- Efforts should also be directed towards improving the behaviour of patients and attendants towards HCWs:

- Educational measures include awareness campaigns on the importance of one attendant policy, the need to wait for their turn and to follow the instructions of HCWs related to treatment, admission and care.

- Regulatory measures include adherence to access restriction policies of hospitals.

For ambulance services:

- It is imperative that the needed services are estimated based on the burden of patients, and standards of maximum response time need to be set.

- Skilled paramedics ensuring promptness and safety while shifting the patients and providing them with standard emergency care would strengthen the confidence of the attendants.

- Financial investment to equip ambulance services per prehospital emergency care standards is also required.

- Awareness campaigns aimed at recognising the limitations of ambulances on roads will help in managing the unreasonable expectations of the people.

- For LHWs and vaccinators, there is a need to revise the strategy to accommodate the concerns of people and build national consensus on existing controversies related to these services.

\section{CONCLUSION}

Violence against healthcare exists in various forms among all cadres and at different levels of care. The gaps in capacity, resources and policies are evident. Specific strategies need to be adopted for different types of HCWs to protect them against violence.

Twitter Samina Zaib @yes

Acknowledgements The authors would like to acknowledge the following: the team leaders at collaborative universities; DG's Health in the three provinces for allowing the data collection; hospital administrators and managers of vertical programmes for facilitating the survey; all the HCWs who shared valuable information; and all the data collectors and supervisors who worked tirelessly in the field to gather quality data.

Contributors SS and LAB conceived the idea, developed the first draft of the proposal, conducted the training of the data collectors, supervised and analysed the data, and wrote the first draft of discussion. IH, MK and SJ assisted in the development of the methodology of the proposal, supervision of data collection, monitored the data entry and contributed to the interpretation of data. MNK, MAS, $\mathrm{KZ}, \mathrm{SE}$, IY and ZH provided technical feedback on proposal and training content, facilitated training, supervised and checked the data, and provided technical input to the analysis and interpretation of data. LM and SZ conducted literature search, and assisted in the development of the research tool and designing the training. They also did the data entry and contributed to developing the tables and graphs of the results.

Funding This study was funded by International Committee of Red Cross.

Competing interests None declared. 
Patient and public involvement Patients and/or the public were not involved in the design, or conduct, or reporting, or dissemination plans of this research.

Patient consent for publication Not required.

Ethics approval Ethical approval of the study was taken from the National Bioethics Committee.

Provenance and peer review Not commissioned; externally peer reviewed.

Data availability statement Data are available upon request to the principal investigator (SS) (shiraz.shaikh@jsmu.edu.pk).

Open access This is an open access article distributed in accordance with the Creative Commons Attribution Non Commercial (CC BY-NC 4.0) license, which permits others to distribute, remix, adapt, build upon this work non-commercially, and license their derivative works on different terms, provided the original work is properly cited, appropriate credit is given, any changes made indicated, and the use is non-commercial. See: http://creativecommons.org/licenses/by-nc/4.0/.

\section{REFERENCES}

1 WHO document. World report on violence and health. Available: www.who.int/violence_injury_prevention/violence/world_report/en/

2 Health policy and Economic Research Unit, British Medical Association. Violence at work: the experience of UK doctors. London: BMA house, 2003.

3 Conseil international des infirmières. Guidelines on coping with violence in the workplace. Geneva: International Council of Nurses, 1999.

4 World Health Organization. Violence: a public health priority. global consultation on violence and health, 1996.

5 Al-Omari H. Physical and verbal workplace violence against nurses in Jordan. IntNurs Rev 2015.

6 Kitaneh M, Hamdan M. Workplace violence against physicians and nurses in Palestinian public hospitals: a cross-sectional study. BMC Health Serv Res 2012;12:469.

7 Donaldson RI, Shanovich P, Shetty P, et al. A survey of national physicians working in an active conflict zone: the challenges of emergency medical care in Iraq. Prehosp Disaster Med 2012;27:153-61.

8 Lafta M, Pandya A. Verbal and physical aggression against resident physicians in two general hospitals in Baghdad. J Muslim Ment Health 2006;1:137-44.

9 Doocy S, Malik S, Burnham G. Experiences of Iraqi doctors in Jordan during conflict and factors associated with migration. $\mathrm{Am} \mathrm{J}$ Disaster Med 2010;5:41-7.

10 Shaw J. Staff perceptions of workplace violence in a pediatric emergency department. Work 2015;51:39-49.

11 Touzet S, Cornut P-L, Fassier J-B, et al. Impact of a program to prevent incivility towards and assault of healthcare staff in an ophtalmological emergency unit: study protocol for the PREVURGO on/off trial. BMC Health Serv Res 2014;14:221.

12 Mirza NM, Amjad Al, Bhatti ABH, et al. Violence and abuse faced by junior physicians in the emergency department from patients and their caretakers: a nationwide study from Pakistan. J Emerg Med 2012;42:727-33.

13 Zafar W, Siddiqui E, Ejaz K, et al. Health care personnel and workplace violence in the emergency departments of a volatile Metropolis: results from Karachi, Pakistan. J Emerg Med 2013:45:761-72.

14 Yousuful-Islam M, Farooq MS, Mazharuddin SM, et al. Workplace violence experienced by doctors working in government hospitals of Karachi. J Coll Physicians Surg Pak 2014;24:698-9.

15 Institute for Conflict Management. Doctors killed in Pakistan 20012014. Available: http://www.satp.org/satporgtp/countries/pakistan/ database/Doctors killed_Pakistan.htm
16 Khan Z. Pakistan's doctors protest at killing of 13 colleagues this year. BMJ 2002;324:805

17 The Newspaper's Staff Reporter. Kidnappers kill doctor after getting RANSOM. Dawn news, 2013.

18 Gadit AAM. Migration of doctors: should we apply the index of Happiness? J Pak Med Assoc 2008;58:342-4.

19 Baig LA, Ali AK, Shaikh S, et al. Multiple dimensions of violence against healthcare providers in Karachi: results from a multicenter study from Karachi. J Pak Med Assoc 2018;68:1157-65.

20 Baig LA, Shaikh S, Polkowski M, et al. Violence against health care providers: a mixed-methods study from Karachi, Pakistan. J Emerg Med 2018;54:558-66.

21 Pinar T, Acikel C, Pinar G, et al. Workplace violence in the health sector in turkey: a national study. J Interpers Violence 2017:32:2345-65.

22 Muzembo BA, Mbutshu LH, Ngatu NR, et al. Workplace violence towards Congolese health care workers: a survey of 436 healthcare facilities in Katanga Province, Democratic Republic of Congo. $J$ Occup Health 2015;57:69-80.

23 Lafta RK, Falah N. Violence against health-care workers in a conflict affected City. Med Confl Surviv 2019;35:65-79.

24 Wei C-Y, Chiou S-T, Chien L-Y, et al. Workplace violence against nurses--prevalence and association with hospital organizational characteristics and health-promotion efforts: Cross-sectional study. Int J Nurs Stud 2016;56:63-70.

25 Li Z, Yan C-M, Shi L, et al. Workplace violence against medical staff of Chinese children's hospitals: a cross-sectional study. PLoS One 2017;12:e0179373.

26 Hasan MI, Hassan MZ, Bulbul MMI, et al. Iceberg of workplace violence in health sector of Bangladesh. BMC Res Notes 2018:11:702.

27 Yenealem DG, Woldegebriel MK, Olana AT, et al. Violence at work: determinants \& prevalence among health care workers, northwest Ethiopia: an institutional based cross sectional study. Ann Occup Environ Med 2019;31:8.

28 Magnavita N, Heponiemi T. Violence towards health care workers in a public health care facility in Italy: a repeated cross-sectional study. BMC Health Serv Res 2012;12:1.

29 Hamdan M, Abu Hamra Asma'a, Abu Hamra A. Workplace violence towards workers in the emergency departments of palestinian hospitals: a cross-sectional study. Hum Resour Health 2015;13:28

30 Algwaiz WM, Alghanim SA. Violence exposure among health care professionals in Saudi public hospitals. A preliminary investigation. Saudi Med J 2012;33:76-82.

31 Azami M, Moslemirad M, YektaKooshali MH, et al. Workplace violence against Iranian nurses: a systematic review and metaanalysis. Violence Vict 2018;33:1148-75.

32 Shafran-Tikva S, Chinitz D, Stern Z, et al. Violence against physicians and nurses in a hospital: how does it happen? A mixedmethods study. Isr J Health Policy Res 2017;6:59.

33 Baig L, Tanzil S, Shaikh S, et al. Effectiveness of training on deescalation of violence and management of aggressive behavior faced by health care providers in a public sector hospital of Karachi. Pak J Med Sci 2018;34:294-9.

34 Swain N, Gale C. A communication skills intervention for community healthcare workers reduces perceived patient aggression: a pretestpostest study. Int J Nurs Stud 2014;51:1241-5.

35 Hemati-Esmaeili M, Heshmati-Nabavi F, Pouresmail Z, et al. Educational and managerial policy making to reduce workplace violence against nurses: an action research study. Iran J Nurs Midwifery Res 2018;23:478-85.

36 Alameddine M, Mourad Y, Dimassi H. A national study on nurses' exposure to occupational violence in Lebanon: prevalence, consequences and associated factors. PLoS One 2015;10:e0137105.

37 Zhang L, Wang A, Xie X, et al. Workplace violence against nurses: a cross-sectional study. Int J Nurs Stud 2017;72:8-14. 